\title{
PROPUESTAS DE FRANZ BRENTANO PARA UNA CORRECTA INTERPRETACIÓN DE ARISTÓTELES
}

\author{
DAVID TORRIJOS-CASTRILLEJO \\ Universidad Eclesiástica San Dámaso (Madrid)
}

\begin{abstract}
RESUMEN: Una parte considerable de los trabajos de Brentano concierne el pensamiento de Aristóteles. Su manera peculiar de interpretar al Estagirita hace de Brentano una figura singular en el ámbito de los estudios aristotélicos de su época. Aunque no rechaza la utilización de los recursos filológicos e históricos para comprender los textos antiguos y él mismo hace amplio uso de ellos, cree que la principal guía para el estudio de la filosofía antigua debe ser la hermenéutica filosófica. Por este motivo, desarrolla una crítica incisiva de la mayor parte de los intérpretes que se ocupaban en sus tiempos del estudio especializado de Aristóteles. Es por esta misma razón que Brentano juzgará como intérpretes más adecuados de la filosofía clásica a los escolásticos medievales y, en particular, a santo Tomás de Aquino. Para comprender su modo de interpretar a Aristóteles, en nuestras páginas examinaremos algunas reglas propuestas por Brentano para aproximarse a la obra aristotélica.
\end{abstract}

PALABRAS CLAVE: Hermenéutica, aristotelismo, Tomás de Aquino, historia de la filosofía.

\section{How to study Aristotle according to Brentano}

ABSTRACT: A considerable part of the work of Brentano from his youth to the end of his life is concerned with the thought of Aristotle. His peculiar way to access Aristotle makes of Brentano a rather eccentric figure among the nineteenth and early twentieth century's Aristotelian scholarship. On the one hand, he doesn't reject emphasizing the use of philological and historical resources in order to understand ancient texts and indeed he makes extensive use of them himself; on the other hand, he believes that the main guide for the study of ancient philosophy should be a philosophical hermeneutics. Therefore, he develops a sharp criticism against Zeller and other scholars. Is for this reason that Brentano considered medieval scholastics as more appropriate interpreters of classical philosophy than them, in particular Aquinas. In our remarks, we will seek to review the main features of the method for interpreting Aristotle defended by Brentano.

KEYWORDS: Hermeneutics, aristotelianism, Aquinas, History of Philosophy.

\section{INTRODUCCIÓN}

La faceta aristotélica de Brentano ha recibido cierta atención principalmente entre dos grupos de estudiosos: quienes intentan penetrar la filosofía personal de este autor pues ven en ella un precedente de ésta y quienes se interesan por la formación de Heidegger. No ha merecido tanto interés esta dimensión de Brentano entre quienes buscan en él al maestro de Husserl, pues, como el mismo Heidegger declaró una vez, quien influyó en Husserl fue el autor de la Psicología desde el punto de vista empírico, mientras que Heidegger comenzó su formación con «el Brentano de Aristóteles» ${ }^{1}$. Atendiendo a esta afirmación,

1 «Er betont, daß Husserls philosophischer Ausgangspunkt Franz Brentano war, der Autor der «Psychologie vom empirischen Standpunkt». Mein eigener Ausgangspunkt, bemerkt er, war derselbe Franz Brentano, - aber nicht mit diesem Werk von 1874; es war vielmehr «Von der mannigfachen Bedeutung des Seienden nach Aristoteles» (Freiburg 1862), worin Heidegger 
Volpi ha desarrollado un principio hermenéutico de comprensión de Brentano, según el cual en él coexistirían dos planteamientos filosóficos bastante divergentes, a saber, uno como intérprete de Aristóteles y otro en su propio pensamiento $^{2}$. Sea cual fuere la relación entre estas dos «almas» de Brentano, lo cierto es que comenzó su carrera con Aristóteles y la cerró con él. Sus primeros y últimos libros están dedicados a este filósofo y constituyen la mayor parte de cuanto logró publicar en vida ${ }^{3}$. Por consiguiente, sus esfuerzos como intérprete del Estagirita no deben ser relativizados. En estas páginas pretendo, pues, fijarme en la postura de Brentano respecto del método de estudio de Aristóteles, algo que nos proporcionará también una buena panorámica de su comprensión del pensamiento del filósofo griego. De este modo nos asomaremos a un episodio de la historia de la filosofía del siglo XX en el cual se advierte el enorme protagonismo del que Aristóteles sigue gozando y nos permite hacernos cargo de la permanente actualidad de su pensamiento.

\section{LA POLÉmica ENTRE BRENTANO y ZELLER}

Para comprender el método de acercamiento a Aristóteles practicado por Brentano, aunque tendré en cuenta el resto de su obra, me centraré sobre todo en un breve manuscrito suyo publicado póstumamente por George cuyo título es: «Sobre el método en los estudios aristotélicos y sobre el estudio de la investigación histórica en ámbito filosófico en general» ${ }^{4}$. A pesar de lo que infiere dicho editor, este trabajo debió de ser elaborado no mucho más tarde de

Philosophie zu lesen gelernt hat. Ein seltsames und bezeichnendes Zusammentreffen bei Husserl und Heidegger, daß beide ihren ersten Schritt mit demselben Philosophen, aber nicht mit dem selben Werk gemacht haben. Mein Brentano, sagt Heidegger lächelnd, ist der des Aristoteles!» («Seminar in Zähringen 1973», en: Heidegger, M., Gesamtausgabe, Band 15, Klostermann, Frankfurt am Main, 1986, pp. 385-386, §§ 123-124).

2 Cf. VolpI, F., «War Franz Brentano ein Aristoteliker?», en: FeILchenfeldt, K., ZaGaRI, L. (eds.), Die Brentano. Eine europäische Familie, Niemeyer, Tübingen, 1992, pp. 129-145.

3 Cf. Brentano, F., Von der mannigfachen Bedeutung des Seienden nach Aristoteles, Herder, Freiburg im Breisgau, 1862; id., Die Psychologie des Aristoteles, insbesondere seine Lehre

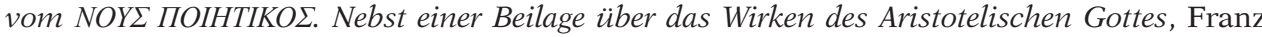
Kirchheim, Mainz, 1867; id., Aristoteles Lehre von Ursprung des menschlichen Geistes, Veit \& Comp., Leipzig, 1911; id., Aristoteles und seine Weltanschauung, Quelle \& Meyer, Leipzig, 1911.

${ }^{4}$ Cf. Brentano, F., «Zur Methode aristotelischen Studien, und zur Methode geschichtlicher Forschung auf philosophischem Gebiet überhaupt», en: George, R. (ed.), Über Aristoteles. Nachgelassene Aufsätze, Meiner Hamburg, 1986, pp. 7-20. El interés de estas páginas lo demuestra la excelente traducción francesa (de Anne Baillot) que merecieron en un imprescindible volumen, publicado hace ya más de un decenio, sobre el aristotelismo en el siglo diecinueve: cf. BRENTANO, F., «Sur la méthode des études aristotéliciennes, et sur l'histoire de la philosophie en général», en: Thouard, D. (ed.), Aristote au XIX ${ }^{e}$ siècle, Septentrion, Villeneuve d'Ascq, 2004, pp. 296-305. Recientemente ha aparecido también mi versión española de este opúsculo: Torrijos-Castrillejo, D., "El método de estudio de Aristóteles según Brentano», Anales del Seminario de Historia de la Filosofía, 33 (2016), pp. 671-688 
$1883^{5}$, cuando - por así decir - aún estaba caliente la disputa mantenida con Zeller. Éste había sido criticado en un trabajo de Brentano de 1867, de modo que respondió a las acusaciones en publicaciones posteriores. Esto empujó a nuestro autor a escribir dos opúsculos en 1882 y 1883 reprochándole su manera de proceder a la hora de estudiar la filosofía de los antiguos ${ }^{6}$. Volvamos brevemente los ojos a esta disputa, que nos permitirá comprender mucho mejor lo que sigue.

Como es sabido, entre 1858 y 1859 Brentano estudió en Berlín junto a Trendelenburg, dedicando en ese tiempo un gran esfuerzo a penetrar en el estudio de Aristóteles. Debe tenerse en cuenta la orientación de la historiografía filosófica llevada a cabo por Trendelenburg. Tal como declaró Bonitz, «la aclaración de la historia de la filosofía no era para él una mera tarea histórica sino un momento esencial de su propia investigación psicológica» ${ }^{7}$. Pese a no compartir todos los puntos de vista de su maestro, Brentano lo sigue sin dudarlo en

5 George propone 1893 como fecha de composición (cf. BREnTANo, Über Aristoteles, p. 542 , nota 12) pero lo hace incurriendo en dos errores importantes. En primer lugar, confunde este escrito con una conferencia pronunciada en la Wiener philosophischen Gesellschaft en abril de 1888, cuyo bosquejo fue publicado a título póstumo poco después del libro preparado por George: Brentano, F., "Zur Methode der historischen Forschung auf philosophischem Gebiet», en: Hedwig, K. (ed.), Geschichte der Philosophie der Neuzeit, Meiner, Hamburg, 1987, pp. 81-94. El segundo error cometido por George —y el más decisivo para la datación- es creer que la primera edición de la más reciente obra de Zeller aludida en esas páginas procedía de 1893, cuando en realidad es de un decenio anterior: Zeller, E., Grundriss der Geschichte der griechischen Philosophie, Fues, Leipzig 1883. De este modo, conviene situar la fecha de composición lo antes posible, de modo que tanto el Grundriss como las publicaciones de Zeller de 1883 y 1883 en las cuales entraría en polémica con Brentano — de las que enseguida hablaremos- puedan seguir siendo consideradas «recientes» por nuestro autor (que usa los adverbios neuerdings, jüngst): cf. BREntano, "Zur Methode aristotelischen Studien», pp. 7, 14. En un escrito mucho más reciente, George parece haber advertido alguno de sus errores pues cambia la datación, pero sigue inclinándose por una fecha algo más tardía que la nuestra, a saber, los últimos años de la década de los ochenta: cf. George, R. and Koenn, G., «Brentano's Relation to Aristotle», en: Jacouette, D. (ed.), The Cambridge Companion to Brentano, Cambridge UP, Cambridge, 2004, p. 44, nota 26.

6 Sobre la polémica entre Zeller y Brentano: cf. Ross, W. D., «Book Review of Franz Brentano. Aristoteles Lehre vom Ursprung des Menschlichen Geistes», en: Mind 23 (1914), pp. 289-291; George, R., "Einleitung», en: Brentano, F., Aristoteles Lehre vom Ursprung des menschlichen Geistes, Meiner, Hamburg, 1980, pp. vii-xiv; MüNcH, D., «Die Einheit von Geist und Leib. Brentanos Habilitationsschrift über die Psychologie des Aristoteles als Antwort auf Zeller», en: Brentano Studien 6 (1995/6), pp. 125-144; George and Koenn, «Brentano's Relation to Aristotle», pp. 37-39; BerTI, E., Aristotele nel Novecento, Laterza, Roma, 2008, pp. 12-13; id., "Zeller e Aristotele», en: id., L'influenza di Aristotele: Età moderna e contemporanea, vol. 4.2, Nuovi studi aristotelici, Morcelliana, Brescia, 2010, pp. 132-133; Mangiagalli, M., Franz Brentano, interprete di Aristotele, Aracne, Roma, 2009, pp. 23-25.

7 «Die Erklärung der Aristotelischen Psychologie ist ihm [Trendelenburg] nicht eine bloss historische Aufgabe, sondern ein wesentliches Moment seiner eigenen psychologischen Forschung»: BonITZ, H., Zur Erinnerung an Friedrich Adolf Trendelenburg, Vortrag gehalten am Leibnitztage 1872 in der königlichen Akademie der Wissenschaften, Akademie der Wissenschaften, Berlin, 1872, p. 14. 
este planteamiento. Es más, hasta el final de su vida se referirá a él como un estudioso de Aristóteles ejemplar, precisamente por no comprender la historia de la filosofía como puro conocimiento histórico; al contrario, según Brentano, Trendelenburg se empapó del espíritu de Aristóteles y se volvió aristotélico, para buscar la verdad al lado del Estagirita ${ }^{8}$.

Fruto del estudio de Aristóteles junto a Trendelenburg fue su primera publicación, su tesis doctoral: Sobre los múltiples sentidos del ser en Aristóteles (1862), donde tan sólo expresaba tímidamente algunos desacuerdos del parecer de Zeller, aunque en general se mostrase en consonancia con él ${ }^{9}$. Sin embargo, años más tarde, en la tesis escrita para su Habilitation, que trataba sobre La psicología de Aristóteles (1867) discrepó por completo de las posiciones de Zeller respecto del entendimiento agente y de Dios. Según Brentano, Zeller habría defendido que el entendimiento agente es una realidad divina exterior al hombre que interviene sobre él cuando piensa, de modo que sería impensable suponer la inmortalidad del alma; en efecto, cuanto de espiritual hay en él no formaría parte de su identidad personal. Respecto de Dios, Zeller habría sostenido que actuaría sobre el mundo meramente como una causa final pero de ningún modo como causa eficiente, pues al contemplarse tan sólo a sí mismo no conocería ningún otro ente fuera de sí. Brentano, por su parte, dedica su trabajo precisamente al entendimiento agente para concluir que forma parte del alma intelectiva y es, por consiguiente, un poder mental humano, no una realidad extraña al hombre. Sin embargo, afirma que sí posee una vinculación directa con la divinidad, pero es merced a haber sido creado por Dios. Esta atrevida afirmación le llevó a añadir un apéndice a su trabajo para demostrar que Dios no sólo es causa eficiente del mundo y conoce cada ente, sino que crea, amén de los espíritus humanos, todo el cosmos. La divergencia del parecer de Zeller no podría ser más acentuada. Pero, además, este libro contiene por primera vez un severo juicio de la obra de Zeller que afecta a todo su proceder y no sólo a sus conclusiones:

Por si no bastare lo peculiar e ilógico de esta teoría para hacernos dudar del acierto de tales resultados, no quedará nada más en absoluto que pueda aconsejarnos esta interpretación una vez hayamos considerado que no pocas declaraciones de Aristóteles se encuentran en manifiesta contradicción con ella. Incluso Zeller mismo lo reconoce [...]. Las mencionadas [varian-

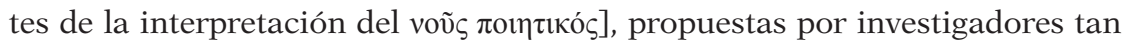
destacados, basten para demostrar las contradicciones y la confusión que es introducida en la doctrina aristotélica a través de cada uno de estos intentos, una confusión que crece tanto más, cuanto más se considera cada una de sus declaraciones. Hay que conceder a Zeller el honor de haber caído en esto más que ninguno y, precisamente por ello mismo, su presentación de esta parte de

8 En un manuscrito sobre el cual volveremos enseguida, pone a Trendelenburg junto a comentaristas como Alberto Magno y Tomás de Aquino: cf. BRentano, Aristoteles Lehre vom Ursprung des menschlichen Geistes, 1980, p. x.

9 Cf. Brentano, Von der mannigfachen Bedeutung des Seienden nach Aristoteles, p. 183. 
la psicología de Aristóteles se manifiesta como una madeja de enredadas representaciones y como un cúmulo de afirmaciones contradictorias entre sí $^{10}$.

Obsérvese que es justamente la contradicción aquello que más enoja a Brentano. Zeller da por sentado que Aristóteles puede caer en la torpeza de sostener una cosa y su contradictoria en diferentes ocasiones y esto es algo que nuestro estudioso considera sencillamente impensable. Por este motivo, en esta obra juvenil ya formula sus planteamientos metodológicos fundamentales en orden a comprender a Aristóteles:

Cuando uno se topaba con pasajes contradictorios, entonces, o bien los rechazaba del todo o los enmendaba, o bien los exponía como acomodaciones a las representaciones de la opinión vulgar o como contradicciones que, aunque estuvieran al alcance de la mano incluso de un niño, no habrían sido notadas por el entendimiento de Aristóteles. Nunca se tratará adecuadamente a este filósofo mientras se esté dominado por tales prejuicios. El aforismo de Maquiavelo divide et impera acaso tenga alguna validez en política, pero es sin duda cierto que en la investigación de un sistema filosófico, y en especial de uno tan perfecto como lo es el del Estagirita, sucede justamente lo contrario. Los pasajes que, tomados por separado, resultan ininteligibles deben ser reunidos para que nos podamos servir de unos para interpretar los otros ${ }^{11}$.

De tal modo tenemos una demostración triple de la rectitud de nuestra interpretación, pues el hecho de ser capaz dicha prueba de resolver las aparentes contradicciones entre ambas doctrinas de nuestro filósofo podría tener,

10 «Wenn aber schon das Sonderbare und Ungereimte dieser Theorie genügt, um an der Richtigkeit solcher Ergebnisse uns zweifeln zu machen, so bleibt vollends nichts mehr, was diese Auffassung empfehlen könnte, übrig, wenn man sieht, wie nicht wenige Aussprüche des Aristoteles in offenbarem Widerspruche damit stehen. Selbst Zeller bekennt dieses

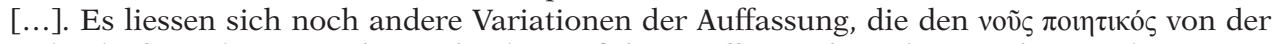
Individualität des Menschen scheidet, anführen, allein schon die erwähnten, die von so ausgezeichneten Forschern versucht worden sind, genügen, um die Widersprüche darzuthun und die Verwirrung, welche nothwendig durch jeden derartigen Versuch in die Aristotelische Lehre gebracht wird und um so mehr sich vergrössert, je mehr man alle einzelnen Aussprüche berücksichtigt. Man muss es Zeller nachrühmen, dass er dies am meisten gethan, aber eben darum erscheint auch gerade nach seiner Darstellung dieser Theil der Aristotelischen Psychologie am meisten als ein Knäuel verworrener Vorstellungen und als eine Anhäufung sich widersprechender Aussagen» (Brentano, Die Psychologie des Aristoteles, pp. 35-36; trad. española, Torrijos-Castrillejo, D., Ediciones Universidad San Dámaso, Madrid, 2015, pp. 47-48; cf. ibíd., p. v; trad. española, p. 1).

${ }_{11}$ «Stiess man dann auf die widersprechenden Stellen, so verwarf man sie entweder geradezu, oder verstümmelte sie, oder erklärte sie für Accommodationen an die Vorstellungen der gewöhnlichen Meinung, oder für Widersprüche, die, obgleich ein Kind sie mit Händen greifen kann, dem Verstande des Aristoteles nicht bemerklich waren. Man wird nie diesem Philosophen gerecht werden, so lange man in solchen Vorurtheilen verharrt. Es mag der Grundsatz des Macchiavelli, divide et impera, in der Politik seine Geltung haben, bei der Erforschung eines philosophischen Systemes, und namentlich eines so vollkommenen, wie das des grossen Stagiriten ist, ist jedenfalls der entgegengesetzte am Platze. Die vereinigten Stellen müssen es sein, die, was für sich allein unverständlich war, uns erklären helfen» (Brentano, Die Psychologie des Aristoteles, pp. 194-195; trad. española, pp. 262-263). 
también para nosotros, la significatividad que para el físico tiene una hipótesis cuando está en condiciones de explicar mediante ella todos los fenómenos de la naturaleza, incluso habiéndose mostrado antes enigmáticos y contradictorios ${ }^{12}$.

En estos pasos encontramos enunciados con claridad varios principios hermenéuticos que rigen el trabajo de Brentano y que conviene identificar ya aquí: [1] no cabe suponer que Aristóteles haya admitido nunca una contradicción abierta y desde luego esto no ha podido suceder por falta de inteligencia; [2] conviene leer a Aristóteles en unidad, teniendo en cuenta la totalidad de su pensamiento y no tomar cada parte por separado; [3] hace falta poner de acuerdo los pasajes aparentemente contradictorios mediante una correcta hermenéutica filosófica; [4] tal cosa es preferible a las correcciones que apelan a factores históricos y accidentales a la filosofía misma, como las emendaciones textuales, el recurso a descuidos redaccionales, a una hipócrita acomodación del Estagirita al sentir vulgar, etc.; [5] una prueba de la validez de una interpretación es su capacidad de explicar muchas tesis distintas (de un modo análogo a como sucede en las ciencias positivas).

Zeller respondió a estas críticas en muchas notas al pie de su tercera edición de su Philosophie der Griechen de $1879^{13}$. A su vez, Brentano contestó a esas réplicas en su Creatianismus des Aristoteles (1882), donde se reafirma en su posición anterior ${ }^{14}$. Zeller tampoco se quedó callado y el mismo año publicó una nueva contrarréplica ${ }^{15}$ a la que siguió, un año después, un enésimo escrito de Brentano como respuesta ${ }^{16}$. Este último tan sólo se vio contestado por un par de páginas de Zeller publicadas meses después ${ }^{17}$. A continuación, ni Brentano contraatacó, ni publicó nada más acerca de Aristóteles hasta los últimos años de su vida. En 1910 vio la luz una recopilación de escritos menores de Zeller (fallecido en 1908) entre los que figuraba el opúsculo de respuesta a Brentano de $1882^{18}$. Esto proporcionó una oportunidad a Brentano de retomar sus

12 «Und so haben wir denn einen dreifachen Beweis für die Richtigkeit unserer Auffassung; denn auch die Thatsache, dass sie allein die scheinbaren Widersprüche zwischen den einen und anderen Lehren unseres Philosophen zu lösen weiss, möchte für uns die Bedeutung haben, die es für den Physiker hat, wenn er durch seine Hypothese alle Erscheinungen der Natur, auch wenn sie vorher räthselhaft und widersprechend schienen, zu erklären im Stande ist» (Brentano, Die Psychologie des Aristoteles, p. 216; trad. española, p. 290).

13 Cf. Zeller, E., Aristoteles und die alten Peripatetiker, vol. 2.2, Die Philosophie der Griechen in ihrer geschichtlichen Entwicklung, Fues, Leipzig, ${ }^{3} 1879$.

14 Cf. Brentano, F., Über den Creatianismus des Aristoteles, C. Gerold's Sohn, Wien, 1882.

15 Cf. Zeller, E., «Über die Lehre des Aristoteles von der Ewigkeit des Geistes», en: Sitzungsberichte der königlich preußischen Akademie der Wissenschaften zu Berlin 1 (1882), pp. 1033-1055.

16 Cf. BREnTANo, F., Offener Brief an Herrn Professor Eduard Zeller aus Anlaß seiner Schrift über die Lehre des Aristoteles von der Ewigkeit des Geistes, Duncker \& Humblot, Leipzig, 1883.

17 Cf. Zeller, E., «Franz Brentano, Ueber den Creatianismus des Aristoteles. Ders., Offener Brief an Herrn Prof. Dr. E. Zeller», en: Deutsche Literaturzeitung 4 (1883), col. 228-230.

18 Cf. Zeller, E., en: Leuze, O. (ed.), Eduard Zellers Kleine Schriften, 1. Band, Reimer, Berlin, 1910, pp. 263-290. 
antiguas discusiones y preparar sus últimos trabajos sobre Aristóteles, ambos publicados en 1911. Uno de ellos constituye prácticamente una reedición de sus escritos de 1882 y 1883 contra Zeller: La enseñanza de Aristóteles sobre el origen del espíritu humano ${ }^{19}$. El otro supone una reflexión nueva en que expone de manera sintética sus puntos de vista principales sobre Aristóteles y cómo ha de ser abordado su estudio, incluyendo algunas críticas al método asumido por Zeller y los que han seguido su estela: Aristóteles y su cosmovisión ${ }^{20}$.

En el escrito al que prestaremos atención para establecer el método de estudio de Aristóteles, Brentano pretende suspender el juicio sobre las destrezas filosóficas de Zeller ${ }^{21}$. Tan sólo lo juzga en cuanto historiador de la filosofía sin poner en duda que Zeller sea capaz de elaborar pensamiento filosófico propio. No obstante, le reprocha que esa capacidad sea preterida por él deliberadamente, con el propósito de alcanzar una presunta objetividad. Achaca la causa de esta actitud a su formación, profundamente influida por el hegelianismo. No es que Hegel le haya indicado que se deba hacer historia de la filosofía omitiendo practicar la filosofía. Nada más lejos de su parecer. Justamente por ello, para apartarse de la Caribdis en que ha caído Hegel, esa abusiva proyección de la propia subjetividad sobre la historia de la filosofía examinada por él, Zeller — horrorizado por los nefastos resultados a que ello arrastraba- se habría precipitado empero en la Escila de una objetividad no menos funesta ${ }^{22}$. Con el pretexto de no poner nada de su parte, habría omitido por completo la hermenéutica filosófica y no se habría esforzado por comprender las cuestiones abordadas por Aristóteles con espíritu de síntesis, buscando antes que nada la coherencia interna del argumento.

\section{LA INSPIRACión tOMista DEL ESTUdio DE ARISTÓteles}

No se debe olvidar el contexto intelectual en que el antedicho debate entre Zeller y Brentano se desenvolvió. A finales del siglo XIX se estaba desarrollando en Europa central la confrontación entre modelos de civilización conocida

19 Cf. Brentano, Aristoteles Lehre von Ursprung des menschlichen Geistes.

20 Cf. id., Aristoteles und seine Weltanschauung.

21 Cf. id., "Zur Methode aristotelischen Studien», p. 11. En ese sentido, no es del todo exacto que Brentano viese en Zeller únicamente «den untalentierten Philologen, der mit geringem systematischen Verständnis an das Werk des Meisters heranging» (GEORGE, «Einleitung», en: Brentano, Aristoteles Lehre vom Ursprung des menschlichen Geistes, 1980, p. ix), sino más bien que no se conducía como filósofo cuando actuaba como historiador de la filosofía, contentándose tan sólo con un método filológico discutible. En atención al texto que estamos comentando, George ajusta un tanto sus palabras en George and KoEHN, «Brentano's Relation to Aristotle», pp. 38-39.

22 Cf. Brentano, «Zur Methode aristotelischen Studien», pp. 7, 11-12; id., «Zur Methode der historischen Forschung auf philosophischem Gebiet», p. 89. 
como Kulturkampf ${ }^{23}$. No es casualidad que Zeller escribiera desde Prusia y Brentano, durante los años en que publicó sus dos primeros libros sobre Aristóteles, hubiese sido primero aspirante al sacerdocio y después clérigo católico. Poco importaba que, a la hora de ser publicados los textos de contrarréplica a Zeller de 1882 y 1883, Brentano hubiese abandonado la Iglesia católica desde hacía años. A los ojos de Zeller, la hermenéutica filosófica de Brentano parecía una restauración de la escolástica plenamente inserta en el movimiento de la Neuscholastik. No le faltaba algún fundamento para ello, pero, en realidad, Brentano siempre fue un espíritu libre y no se sentía ligado por ninguna escuela de pensamiento ${ }^{24}$. Eso sí, en su forma de aproximarse a un texto, se sentía más cercano a santo Tomás de Aquino que a los historiadores contemporáneos.

Antes de nada, debe dejarse claro que Brentano no desdeña los recursos del método histórico ni filológico; es más, hace amplio uso de ellos en sus propios estudios. En su mocedad adquirió considerables conocimientos de lenguas clásicas, como lo demuestran sus obras. Sin embargo, santo Tomás y los escolásticos, al igual que los antiguos peripatéticos, poseen un mérito superior como comentaristas en comparación con quienes tan sólo emplean recursos filológicos, porque son capaces de filosofar con Aristóteles. La tesis principal de Brentano es que la ciencia histórica y filológica solas no bastan para interpretar a un filósofo; es menester que quien se aplique a esta tarea sea también filósofo:

23 Cf. Berti, «Zeller e Aristotele», p. 132. Sobre el episodio histórico: cf. Freudenthal, H. W. L., «Kulturkampf», en: New Catholic Encyclopedia, vol. 8, McGraw-Hill, New York, 1967, pp. 267-269. En concreto, es importante comprender el contexto intelectual en que se mueve Brentano, ligado, a través de Clemens, a la neoescolástica: cf. Tomasi, P., Una nuova lettura dell'Aristotele di Franz Brentano alla luce di alcuni inediti, Uni Service, Trento, 2009, pp. 27-36.

${ }_{24}$ Considero muy acertada la reflexión de George: «This book [Die Psychologie des Aristoteles] has occasionally been called a Thomist interpretation of De Anima. This is somewhat misleading. It is of course true that a Catholic philosopher writing in 1866 would be influenced by the Thomist movement, and it is also true that Brentano finds himself in closer agreement with St. Thomas than with any of the other philosophical commentators he considers. But it is patent, surely, that Brentano did not write this book with St. Thomas' commentary at his elbow, and that the line of argument, as well as many substantive points are entirely independent of St. Thomas' teaching. My conjecture is that the book's reputation derives from the fact that Brentano consulted Thomas and other Medievals at all, which was then not de rigueur among historians of ancient philosophy and thought contrary to the Historical Method» (George, R., «Editor's Preface», en: Brentano, F., en: George, R. [trad., ed.], The Psychology of Aristotle. In Particular His Doctrine of the Active Intellect. With an Appendix Concerning the Activity of Aristotle's God, University of California, Berkely/Los Angeles/London, 1977, p. x). Dan buena prueba de su libertad frente a la doctrina de santo Tomás sus significativas críticas a ella en el libro al que se refiere George, algo que sería bien extraño en un autor pretendidamente «tomista»: cf. Die Psychologie des Aristoteles, pp. 228-229, trad. española, pp. 305-306. De esta misma época es la siguiente áspera crítica a la neoescolástica: «3. Richtung: Neuscholastiche, welche sosehr in Verruf gekommen. Freilich sind sie noch nicht recht auf die rechte Fahrt gekommen, vielfach knüpfen sie zu viel an das Verfallende an» (BRENTANo, Ms. perteneciente a las Vorlesungen der Geschichte der Philosophie, 1866/67, citado por Tomasi, Una nuova lettura dell'Aristotele di Franz Brentano alla luce di alcuni inediti, p. 32). 
No todo filólogo se dedicará a exponer a un Euclides o a un Arquímedes sino tan sólo aquel que también sea matemático. Ni tampoco todo historiador se atreverá a escribir una historia de la química y de la física con feliz resultado excepto uno que a la vez sea naturalista. Del mismo modo, pues, ha de exigirse un filósofo para investigar la historia de la filosofía ${ }^{25}$.

Por este motivo, concluye Brentano, quienes mejor han interpretado a los filósofos antiguos han sido justamente aquellos más dotados para la investigación filosófica: «De ahí la superioridad de los trabajos histórico-filosóficos de un Aristóteles, un Alberto y un Tomás, un Trendelenburg. De ahí las distorsiones de un Zeller y de un Gomperz » ${ }^{26}$. Brentano cree que existe una línea de continuidad entre los intérpretes de Aristóteles que son a la vez filósofos y tratan de pensar de acuerdo con él e inspirándose en él. Así se explicaría cómo Trendelenburg, a pesar de ser moderno e incluso de confesión protestante, reconociese en santo Tomás un comentarista digno de atención ${ }^{27}$. Es más, Brentano afirma que existe un cierto «parentesco» espiritual entre estos pensadores. Él mismo no duda en sumarse a la línea de sucesión arriba enunciada y, así, de modo expresivo, afirmará al final de su vida, evocando lo que años antes había declarado a un alumno suyo:

De qué raza desciendo, oídlo, vosotros, los coronados con blasones.

Semilla soy de Sócrates, el que a Platón produjo.

Platón engendró el vigor de Aristóteles, nunca envejecido,

Como no se marchitó la novia que él, amante, se escogió.

Dos milenios pasaron, aún florece y da brotes el himeneo aquel;

Aun hoy, me glorío de proceder de ese consorcio y no de otro.

A ti, Eudemo, el piadoso, saludo cual a hermano,

Y a ti también, Teofrasto, el de boca divina, dulce como el vino de Lesbos.

Por haberle sido yo ofrendado tarde y ser el más joven de los suyos,

El padre me ha preferido tiernamente a todos los demás ${ }^{28}$.

25 «Nicht jeder Philologe wird es unternehmen, einen Euklid oder Archimedes zu exponieren, sondern nur der, welcher auch Mathematiker ist. Und nicht jeder Historiker wird sich mit Glück an eine Geschichtsschreibung der Chemie und Physik wagen, außer ein solcher, der zugleich Naturforscher ist. So wird denn auch zur Erforschung der Geschichte der Philosophie ein Philosoph zu verlangen sein» (BREntano, "Zur Methode aristotelischen Studien», p. 10, traducción española, p. 678. Cf. id., «Zur Methode der historischen Forschung auf philosophischem Gebiet», p. 89).

26 «Daher die Superiorität der historisch-philosophischen Arbeiten eines Aristoteles, eines Albertus und Thomas, eines Trendelenburg. Daher die Verzerrungen eines Zeller und Gomperz» (BREnTANo, ms. citado por George, «Einleitung», en: Brentano, Aristoteles Lehre vom Ursprung des menschlichen Geistes, 1980, p. x).

27 Cf. Brentano, Aristoteles Lehre vom Ursprung des menschlichen Geistes, 1811, p. 2, nota.

28 «Welchem Geschlecht ich entsprang ihr Wappengekrönten, vernehmet! / Sokrates' Same bin ich, welcher den Plato gezeugt. / Plato zeugt' Aristoteles' Kraft, die nimmer gealtert, / Wie nicht welkte die Braut, die er sich liebend erkor. / Zwei Jahrtausende flohn, noch blüht und sprosset die Ehe; / Denn nicht anderem Bund rühm' ich mich heute entflammt. / Dich, Eudemus, du frommer, begrüß' ich als Bruder, und dich auch, / Göttlichen Mund's, 
Ese parentesco espiritual con Aristóteles del cual Brentano se siente beneficiario, es justamente el que advierte en Tomás. La continuidad entre Tomás y Aristóteles es tan grande que, en una carta juvenil, después de haber confirmado la línea sucesoria recién expuesta afirmando que «la filosofía de Platón y la de Aristóteles es una y la misma ${ }^{29}$, escribirá que Platón sólo aventajó a Aristóteles en una cosa, a saber, en haber sido capaz de engendrar un discípulo de su misma talla, algo que el Estagirita no lograría sino muchos siglos después en la persona del Aquinate ${ }^{30}$.

Por esta peculiar vinculación con Aristóteles, el Aquinate ocupó un lugar especial en la atención de Brentano ${ }^{31}$. Sin embargo, le dedicó un espacio bastante pequeño en sus publicaciones. Además de referencias más o menos breves en diferentes lugares, se ocupó temáticamente de él en su Historia de las ciencias eclesiásticas y sobre todo en un artículo publicado en sus últimos años

Theophrast, süß wie der Lesbische Wein. / Weil ich spät ihm geschenkt und der Jüngste im Kreise der Seinen, / Hat vor anderen mich zärtlich der Vater geliebt» (BRENTANo, Aristoteles und seine Weltanschauung, pp. iv-v, trad. española, SÁnchez BARRADo, M., Labor, Barcelona, 1983, p. 7, retocada ligeramente por mí).

${ }_{29}$ «Der gelehrte Simplicius hat bekanntlich ausführliche Commentare zu den Kategorien und zu den Auscultationes Physicae des Aristoteles geschrieben. In beiden Büchern gibt er sich viele Mühe, zu zeigen, daß Plato und Aristoteles wohl zu vereinigen seien. Auch Cicero sagt in gleicher Meinung, die Aristotelische und Platonische Philosophie seien ein und dieselbe. In der That bin ich mit diesen beiden Männern ziemlich einverstanden. Die Platonische und Aristotelische Philosophie sind Eine; denn es gibt überhaupt nur Eine Philosophie, nur Eine Weisheit, wie es nur Eine Gottheit, Eine Wahrheit gibt; was außer ihr, gegen sie von Menschen gedacht wird, ist Thorheit. So kann also die Philosophie des Plato nicht mit der des Aristoteles in Widerspruch und Feindschaft gerathen, wo Beide sich widersprechen, thun sie es nicht als Philosophen, wie auch, um mit Plato zu reden, der Arzt nicht, insofern er etwas nicht versteht und falsch behandelt, Arzt genannt werden darf. Die platonische und Aristotelische Philosophie also sind ein und dieselbe» (Brief 16. Februar 1863, en: Nettesheim, J., "Christoph Bernhard Schlüter und Franz Brentano. Zwei unbekannte Briefe Brentanos», en: Zeitschrift für Philosophische Forschung 16 [1962], pp. 294-295).

30 «[...] aber in manchem und zumal in Einem muß er [sc. Aristoteles] dem Plato weichen, einen so großen Schüler hatte er nicht erweckt, wenigstens zu seinen Zeiten nicht mehr, wenn wir auch wohl über Jahrhunderte hinwegschreitend in dem h. Thomas von Aquin einen solchen erkennen mögen» (ibíd., p. 295).

31 Sobre la relación de Brentano con el Aquinate: cf. GILson, É., «Franz Brentano's Interpretation of Medieval Philosophy», en: McAlister, L. L. (ed.), The Philosophy of Brentano, Duckworth, London, 1976, pp. 56-67; Gallardo, S., «Brentano y el Aquinate», en: Espíritu 53 (2004), pp. 279-295; MüNCH, D., «Franz Brentano und die katholische AristotelesRezeption», en: Chrudzimski, A., Huemer, W. (eds.), Phenomenology and Analysis. Essays in Central European Philosophy, Ontos, Frankfurt, 2004, pp. 159-198; Hedwig, K., «,Eine gewisse Kongenialität‘. Brentanos Rückgriff auf Thomas von Aquin in seiner Dissertation», en: Tănăsescu, I. (ed.), Franz Brentano's Metaphysics and Psychology, Zeta, Bucharest, 2012, pp. 95-131; Russo, A., "San Tommaso ed Aristotele nella formazione di Franz Brentano», en: Angelicum 1 (2013), pp. 247-278. Durante los breves años de enseñanza en Würzburg, Brentano enseñó también filosofía medieval: cf. Hedwig, K., «Vorwort», en: Brentano, F., Geschichte der mittelalterlichen Philosophie, Meiner, Hamburg, 1980, pp. ix-xxi. 
intitulado Tomás de Aquino ${ }^{32}$. En la segunda de ellas, Brentano afirma que el de Aquino gozaba de aquella afinidad con el Estagirita de la cual hablábamos antes: era miembro de esa "familia de filósofos» que, como acabamos de ver, encuentra su último vástago en el filósofo alemán mismo. Expresa este parentesco como una afinidad espiritual (Kongenialität) entre Aristóteles y Tomás ${ }^{33}$. Su prestancia como comentarista estriba en esto: en la total asimilación entre intérprete e interpretado, confundiéndose la subjetividad de uno y otro ${ }^{34}$. Se trata de la misma tesis sostenida en uno de sus escritos juveniles, donde ve en él al mayor discípulo del Estagirita de todos los tiempos:

Así, tenemos aquí un fenómeno que vuelve a sorprendernos frecuentemente cuando tratamos a este intérprete: que, a pesar de no arreglárselas bien con las palabras, se adentra en la mente de Aristóteles, algo incomprensible sin una íntima afinidad de espíritu entre ambos varones. Por consiguiente, uno perdona gustosamente las pequeñas imperfecciones y se admira más bien por la penetrante finura de quien, en comparación con nosotros, estaba privado de todo auxilio y ni tan siquiera dominaba la lengua griega; una finura tal que supo suplir todas las herramientas de este tipo hasta el punto de internarse felizmente tanto en ésta cuanto en otras de las más oscuras doctrinas de Aristóteles ${ }^{35}$.

Tal afinidad espiritual (Geistesverwandtschaft) con Aristóteles que, como hemos visto, comparten Trendelenburg, Brentano y santo Tomás, en cuanto «filósofos de raza», tiene la consecuencia indirecta de establecer vínculos también entre ellos. Por este motivo, en el artículo sobre el Aquinate al que nos referíamos, Brentano subraya la ascendencia del teólogo dominico, haciendo notar que en él se da una beneficiosa mezcla de sangre germánica con la

32 Cf. Brentano, F., «Geschichte der kirchlichen Wissenschaften», en: Möhler, J., A. (ed.), Kirchengeschichte, Band 2, Manz, Regensburg, 1867, pp. 550-556; BRENTANO, F., «Thomas von Aquin», en: Neue Freie Presse 15683 (18/4/1908), pp. 1-5. He traducido al español ambos artículos, en Torrijos CAstrillejo, D., «Franz Brentano y Tomás de Aquino», en: Espíritu, 65 (2016), pp. 525-555.

33 Cf. id., «Thomas von Aquin», p. 3.

34 «In order to diminish the «danger» which this purely intellectual approach might carry with it, Brentano insists not only that an interpretation should «mirror» (widerspiegeln) the text but also that the interpreter should "transform his own subjectivity into the author», trying to "assimilate» (verähnlichen) himself to him. This «assimilation» (Verähnlichung) is the main requisite for being able to understand a text» (HedwiG, K., "Brentano's Hermeneutics», en: Topoi 6 [1987], p. 6).

35 «So haben wir hier eine Erscheinung, die bei diesem Erklärer zum Verwundern häufig wiederkehrt, dass er nämlich, obwohl er sich mit den Worten nicht ganz zurecht findet, in den Geist des Aristoteles eingeht, was ohne die innige Geistesverwandtschaft der beiden Männer nicht begreiflich wäre. Darum verzeiht man auch gerne die kleinen Unvollkommenheiten, und staunt vielmehr über einen Scharfsinn, der ihm, da er doch mit uns verglichen von allen Hilfsmitteln entblösst und nicht einmal der griechischen Sprache mächtig war, alles dies in der Art zu ersetzen wusste, dass er sowohl in diese, als in andere der dunkelsten Lehren des Aristoteles glücklich eingedrungen ist» (Brentano, Die Psychologie des Aristoteles, p. 228, trad. española, p. 306). 
italiana $^{36}$. ¡Qué casualidad!, lo mismo que sucede en la familia Brentano. Pero sobre todo resulta interesante el paralelismo que tácitamente se advierte entre las declaraciones de Brentano sobre sí mismo en una carta, retomadas después en Aristóteles y su cosmovisión, con la experiencia de Tomás. Nuestro autor explica que el Aquinate recurriese a Aristóteles aseverando que «el aprendiz tiene que sujetarse a un maestro ${ }^{37}$. Justamente es así como Brentano explica que él mismo recurriera a Aristóteles, guiado por Tomás, para remediar la oscuridad decadente del tiempo en que él mismo vivía:

Inicialmente, como inexperto, hube de adherirme a un maestro y, habiendo nacido en un tiempo de la más penosa decadencia de la filosofía, no pude hallar ninguno mejor que el viejo Aristóteles, para cuya no siempre sencilla comprensión tenía que valerme frecuentemente de Tomás de Aquino ${ }^{38}$.

Probablemente esta afirmación debe de inspirarse en un pensamiento expresado por su maestro Trendelenburg en un libro que Brentano manejó. Allí se refería al final del medioevo como un retorno a Aristóteles, a quien dirigían sus ojos los espíritus humanistas tal como los muchachos griegos volvían la mirada a los esclavos encargados de llevarles de la mano (sus "pedagogos») ${ }^{39}$. Brentano siempre reconoció agradecido la deuda contraída con Aristóteles y con todos los merecedores de ser tenidos como sucesores suyos. Sin embargo, es notorio que, precisamente por seguirlos en cuanto filósofos, es decir, sumándose a ellos en la tarea de comprender la realidad, se sintió obligado a discrepar de muchas de sus ideas. Del mismo modo que no temió apartarse de Trendelenburg en algunos puntos al escribir su tesis doctoral, no temerá después separarse en ciertos detalles de Tomás e, incluso, llegado el momento de componer sus obras filosóficas personales, se le hará imposible sostener varias afirmaciones fundamentales del pensamiento aristotélico. Con esto se quiere decir que Brentano está lejos de adherirse ciegamente a un maestro, sino que se

36 Cf. id., «Thomas von Aquin», p. 1.

37 «Der Lehrling muß sich an einen Meister anschließen» (ibíd., p. 5, traducción española, p. 552).

38 «Ich hatte mich zunächst als Lehrling an einen Meister anzuschließen und konnte, in einer Zeit kläglichsten Verfalles der Philosophie geboren, keinen besseren als den alten Aristoteles finden, zu dessen nicht immer leichtem Verständnis mir oft Thomas v. A. dienen müßte» (Brentano, F., Brief 21. März 1916, citado por: Kraus, O., Franz Brentano. Zur Kenntnis seines Lebens und seiner Lehre. Mit Beiträgen von Carl Stumpf und Edmund Husserl, Beck, München, 1919, p. 31). Estas palabras recuerdan a estas otras publicadas por él unos años antes: «[...] wie ich denn selbst nur eine Dankespflicht erfülle, wenn ich bekenne, daß, als ich mich als Jüngling in einer Zeit tiefsten Verfalls mit der Philosophie zu beschäftigen begann, ich durch keinen Lehrer mehr als durch Aristoteles in eine entsprechendere Forschungsweise eingeführt worden bin» (Brentano, Aristoteles und seine Weltanschauung, p. iv).

39 «[...] da kehrte man sich auch gegen den Lehrmeister und Schutzherrn, unter welchem sich die alte in den Geistern befestigt hatte; man schlug zum Theil mit solchem Unverstand und zugleich mit solcher Lust auf den Aristoteles los, wie etwa griechische Knaben auf ihren Pädagogen» (Trendelenburg, A., Historische Beiträge zur Philosophie, 1. Band, Bethge, Berlin, 1846, p. 251). 
deja guiar por él con el objeto de extender las alas del pensamiento, para continuar el vuelo él solo, sacando provecho - eso sí- de los errores y los aciertos de sus predecesores. Tomás es, pues, autoridad sobre todo como pensador, al igual que Aristóteles; de tal manera, escudarse en las palabras de ambos para omitir el cometido de pensar, lejos de constituir una honra para ellos, sería la mayor de las deshonras con que cabría ultrajarlos ${ }^{40}$.

En definitiva, la afinidad espiritual con Aristóteles permite a santo Tomás comportarse como un filósofo que entiende los caminos recorridos por su antecesor mejor que nadie porque busca lo mismo que él: la verdad de las cosas ${ }^{41}$. Esto es lo propio de la hermenéutica filosófica en detrimento de la mera «historia de la filosofía $»^{42}$. Quien sea de veras filósofo reconocerá mejor los procedimientos investigadores seguidos por Aristóteles o cualquier otro pensador, porque él mismo ha buscado una respuesta a esas preguntas. Para Brentano, el auténtico intérprete no puede conformarse con averiguar qué ha pensado el Estagirita, sino que ha de interesarse ante todo por la realidad y los fenómenos y querer dar una explicación.

Sin duda, es éste el espíritu del mismo Tomás de Aquino, el cual, a su vez, no hace sino apropiarse la hermenéutica practicada por el mismo Aristóteles - a la cual se refirió antes Brentano-: «El estudio de la filosofía no tiene el objeto de conocer qué han pensado los hombres sino averiguar la verdad de las cosas ${ }^{43}$. Se trata del proceder que transmitieron a Brentano tanto sus maestros escolásticos cuanto su iniciador en Aristóteles, Trendelenburg. Por este motivo, las dotes filosóficas son precisas para acometer el comentario de un filósofo y, así, Brentano sentenciará irónicamente - parafraseando Mt 8,22 // Lc 9,60-: «Dejad a los filosóficamente muertos enterrar a sus muertos» ${ }^{44}$.

\section{Las REglas de hermenéutica Filosófica PARA COMPRENDER a ARISTÓteles}

Fijarnos en santo Tomás de Aquino no sólo está motivado por su incomparable relevancia histórica. Es verdad que Brentano subraya su puesto crucial para la recepción de Aristóteles en occidente y cita, ya en su primera obra, la célebre sentencia de Pico della Mirandola: «Sine Thoma mutus esset Aristoteles» ${ }^{45}$.

40 Cf. Brentano, «Thomas von Aquin», p. 4.

${ }^{41}$ "Wie sehr würden sie die Lehren entstellt wiedergeben und uns statt ihrer einen Gallimathias zum besten geben, wenn sie nicht immer zugleich den Blick auf die Tatsachen gerichtet hielten, über welche die betreffenden Forscher handelten» (id., "Zur Methode der historischen Forschung auf philosophischem Gebiet», p. 89).

42 «Die Philosophie [ist] interessanter als die Geschichte» (id., Geschichte der Philosophie der Neuzeit, p. 77).

43 «[...] studium philosophiae non est ad hoc quod sciatur quid homines senserint, sed qualiter se habeat veritas rerum» (De Caelo et mundo, I, lect. 22, §228).

44 «Laßt die philosophisch Toten die Toten begraben» (Brentano, «Zur Methode der historischen Forschung auf philosophischem Gebiet», p. 92).

45 Cf. Brentano, Von der mannigfachen Bedeutung des Seienden nach Aristoteles, p. 181. 
Hacia el final de su vida afirmará algo similar, diciendo que Aristóteles sólo pudo llegar a convertirse en uno de los hombres más influyentes en la historia del pensamiento gracias a la labor transmisora del Aquinate ${ }^{46}$. Sin embargo, ni el puesto que santo Tomás ocupó en la historia ni en el itinerario personal de Brentano son tan significativos para éste como las dotes de auténtico filósofo por las que se distingue el Aquinate. Eso es lo que le convierte - a los ojos de nuestro filósofo- en un comentarista ejemplar.

Para ilustrar la insustituible capacidad que adorna a un verdadero filósofo y hace de él el más deseable comentarista de literatura filosófica, Brentano narra una anécdota autobiográfica en la cual ve reflejada esa disposición intelectual ${ }^{47}$ : estaba acompañando al célebre arqueólogo Otto Benndorf mientras éste trataba de recomponer diferentes fragmentos de esculturas traídos de un reciente viaje por Asia Menor. Al parecer, pese a sus grandes conocimientos históricos y arqueológicos, no era capaz de adivinar a qué partes de las esculturas originales podrían haber pertenecido dichos pedazos. Sin embargo, cuando se le solicitó ayuda al escultor Caspar vom Zumbusch, los resultados fueron mucho más halagadores. Enseguida el artista intuyó con gran agudeza a qué lugar correspondía cada una de las piezas, logrando recomponer las esculturas con mucho mayor acierto y facilidad. Sin duda, Brentano encuentra un claro paralelismo de la erudición histórica del arqueólogo, estéril no obstante para engendrar arte, con la destreza filológica y los conocimientos históricocríticos de quienes pretenden pasar por historiadores de la filosofía sin ser ellos mismos filósofos. Tan sólo un filósofo puede comprender enteramente la obra filosófica recibida porque él mismo se dedica a la investigación en filosofía. No es un experto en palabras, sino en realidades, porque la filosofía se ocupa de éstas y no de aquéllas. Esto se torna especialmente cierto cuando se trata de elucidar «un filosofema truncado e incomprensible» ${ }^{48}$. Tan sólo quien atienda a los mismos hechos que tiene ante los ojos el filósofo que debe ser interpretado será también capaz de comprender cada una de sus frases sueltas, por más que se le oculten ciertos datos. En efecto, un hombre tal dispondrá en su mente de una visión de conjunto que se le escapa a quien se centre tan sólo en las piezas desmembradas tomadas por separado.

Tener en cuenta la unidad orgánica del pensamiento de un filósofo es una de las reglas primordiales que se deben seguir cuando es interpretado. Merced a ella, cabe colegir por analogía cuáles puedan ser las partes que faltan, debido a la mutua conexión que éstas deben guardar entre sí. Tal es el método que Georges Cuvier propuso para la anatomía comparada y que Brentano considera idóneo para la historiografía filosófica. He aquí otro de los motivos que recomiendan los comentarios de santo Tomás:

46 Cf. id., «Thomas von Aquin», p. 2.

47 Cf. ibíd., p. 3; id., «Zur Methode aristotelischen Studien», pp. 10-11.

48 «Dann aber ebenso in dem vollkommen parallelen Falle verstümmelter und unverständlicher Philosopheme» (id., "Zur Methode aristotelischen Studien», p. 11). 
[Tomás de Aquino] se sirvió de un método que sin duda ha de verse coronado por el éxito cuando uno trata con expresiones parcas, concisas, con frecuencia fragmentarias y en ocasiones ambiguas, como las que se encuentran en las obras aristotélicas. Tomás tiene siempre ante los ojos la totalidad de la doctrina aristotélica, en la cual vivía y se entretejía su propio pensamiento, de manera que trataba de entender la parte en función del todo. Tiene en cuenta en cada caso la función propia y la conduce hasta sus consecuencias: lo conoce como Cuvier quien, a partir del dictamen sobre un órgano singular, emitía una previsión acerca de otro, correspondiente con él ${ }^{49}$.

En efecto, la figura de Cuvier será retomada pocos años después de la composición de las líneas que acabamos de leer para explicar cómo se debe reconstruir la doctrina aristotélica:

La estructura ideológica de un gran pensador se parece al organismo de un ser vivo, en que la estructura de una parte condiciona la de otra, y lo que consiguió Cuvier con los restos de los animales prehistóricos — por la naturaleza de las partes existentes determinar del modo más exacto la de las partes que faltaban-, eso mismo debe ser posible en una obra de filosofía como la de Aristóteles. Y llegando así a la plena comprensión del verdadero carácter del todo, de modo que haga evidente la afinidad de este pensador con otros cuyas obras se conservan más completas, esa perspectiva nos proporcionará nuevos medios de interpretación y nos llevará a la más fácil comprensión de un caso por analogía con otro ${ }^{50}$.

49 «Andererseits bedient er sich einer Methode, welche, wo es sich um karge, oft knappe, oft fragmentarische, im einzelnen mehrdeutig Aeußerungen handelt, wie sie uns in den aristotelischen Werken vorliegen, allein von Erfolg gekrönt sein kann. Thomas hat immer das Ganze der aristotelischen Lehre vor Augen, in der ja sein eigenes Denken lebt und webt und sucht die Teile aus dem Ganzen zu begreifen. Er beachtet von jedem die eigentümliche Funktion und führt sie zu ihren Folgerungen; er weiß es wie Cuvier, auf dem Befund eines einzelnen Organes ein anderes hinzugehöriges vorzunahmen» (id., «Thomas von Aquin», pp. 2-3, traducción española, p. 544). Puede que, tal como afirmó MüNch («Franz Brentano und die katholische Aristoteles-Rezeption», p. 175, nota 44), la manera de Brentano de comprender a Tomás como intérprete se fundara hasta cierto punto en las afirmaciones de Franz von Paula Morgott, el autor que escribió sin firmarlo el artículo "Aristoteles und die katholische Wissenschaft», en: Der Katholik 41 (1862), p. 270: «[...] erfüllte er [sc. Thomas von Aquin] seine Lücken [sc. des Aristoteles] und leitete er die Fortentwicklung desselben. Er enthält in sich den ganzen Aristoteles». Obsérvese que aparecen dos rasgos también presentes en el texto citado: que Tomás completa la doctrina de Aristóteles rellenando sus lagunas y que posee una visión de conjunto del pensamiento del Estagirita al haberlo asimilado en su propio pensamiento.

50 «Der Gedankenbau eines großen Denkers gleicht dem Organismus eines Lebewesens, wo die Beschaffenheit eines Teils die des anderen bedingt, und was Cuvier bei den Resten vorweltlicher Tiere gelang, daß er nämlich aus der Natur der gegebenen die Natur der fehlenden Teile aufs treffendste bestimmte, das wird darum auch bei einem solchen Werke der Philosophie oft recht wohl möglich sein. Und ist man so zu dem volleren Verständnis des wahren Charakters des Ganzen gekommen, so daß die Verwandtschaft dieses Denkers mit anderen, deren Werke uns vollkommener erhalten vorliegen, unverkennbar geworden ist, so wird auch der Blick auf diese neue Hilfe leisten und uns dazu fuhren, den einen Fall in Analogie zum anderen leichter zu begreifen» (Brentano, Aristoteles und seine Weltanschauung, p. 15 , trad. española, p. 25, retocada por mí). 
Estos pasajes señalan un rasgo evidente del texto aristotélico observado por Brentano desde su juventud: su estilo literario, caracterizado en unas ocasiones por la fragmentariedad, la ambigüedad en otras, así como la concisión al expresar las afirmaciones más importantes ${ }^{51}$. En el escrito sobre el método de estudio de Aristóteles se atreverá a denominarle «con mucho mayor motivo que a Horacio, obscurus, es más, obscurissimus ${ }^{52}$. El intérprete se encuentra, pues, con un material en penoso estado, con muchos huecos incompletos que se ve obligado a rellenar para tener una visión íntegra de la filosofía del autor en cuestión. Por eso Brentano ve su tarea comparable con la de un arqueólogo que debe restaurar piezas deterioradas o truncadas, o la de un paleontólogo que hubiese de recomponer un esqueleto fragmentario perteneciente a una criatura hace siglos desaparecida. Este paralelismo con las ciencias positivas nos permite comprender mejor el acercamiento de Brentano, porque desde sus años juveniles ha afirmado que «el verdadero método de la filosofía no es sino el de las ciencias naturales ${ }^{53}$. Por este motivo, la industria empleada en desentrañar el texto aristotélico no es un arte extraña a la tarea filosófica sino al contrario, forma parte de ella. Brentano cree que la filosofía ha de atenerse a los hechos positivos tal como son presentados por la experiencia. De acuerdo con eso, cree que el comentarista de Aristóteles deberá guiarse por el cálculo de probabilidades para alcanzar la correcta inteligencia de su pensamiento. En el discurso de 1888 acerca del método en historiografía filosófica, Brentano se inclinaba por él para comprender a un autor:

De tal modo, uno choca con las leyes del cálculo de probabilidades, según las cuales una hipótesis en sí misma muy improbable en un principio, al ser formulada para explicar la causa de un hecho dado, puede volverse muy probable e incluso ser tenida por cierta, porque de otro modo ese hecho resultaría incomparablemente más improbable. Si hubiera dos hipótesis tales que cada una de ellas por separado pudiera justificar cierto hecho, teniendo

51 «Es ist eigenthümlich, dass Aristoteles oft gerade an jenen Stellen, wo er die wichtigsten Lehrpuncte berührt, seine Worte so kurz zusammendrängt, dass sie fast unverständlich werden, während er bei anderen, die bei weitem nicht dasselbe Interesse und dieselbe Schwierigkeit darbieten, sich in weitläufigere Erörterungen einlässt» (BRENTANO, Die Psychologie des Aristoteles, p. 166). «Und daraus erklärt sich aufs einfachste das, was so viel Staunen erregt und Ärgernis erweckt hat, daß Aristoteles gerade da, wo er auf die allerwichtigsten und schwierigsten Fragen zu sprechen kommt, durch Wortkargheit ganz besonders dunkel wird» (id., Aristoteles und seine Weltanschauung, p. 20; cf. pp. 9-11).

52 «Denn bei der Vieldeutigkeit der aristotelischen Termini, auch der von dem Philosophen selbst erfundenen, bei der seiner Ausdrucksweise eigentümlichen Berücksichtigung fremder, namentlich platonischer, Anschauungen, von welchen er zu den seinigen hinüberführen möchte, bei seiner ungenauen Bequemlichkeit in der Wahl von halbentsprechenden Ausdrücken und seiner nachlässigen Schreibweise überhaupt, endlich bei einer Wortkargheit ohne gleichen, die ihn für sich allein schon oft viel mehr als Horaz zu einem obscurus, ja obscurissimus werden lassen müßte [...]» (id., «Zur Methode aristotelischen Studien», p. 8).

53 "Vera philosophiae methodus nulla alia nisi scientiae naturalis est» (BRENTANo, F., Über die Zukunft der Philosophie nebst den Vorträgen Über die Gründe der Entmutigung auf philosophischen Gebiet, Über Schellings System sowie den 25 Habilitationsthesen, Meiner, Hamburg, 1968, p. 136). 
una en principio una probabilidad de 1/100 frente a la otra, con una probabilidad de 1/1.000.000, entonces, por motivo de la realidad que ha de explicarse, adquiriría una probabilidad de 10.000 contra 1; así, al final tendría que ser considerada altamente probable ${ }^{54}$.

Al parecer, Brentano estudió con mucho interés el método del cálculo de probabilidades ${ }^{55} \mathrm{y}$, como vemos, lo aplicará para las hipótesis hermenéuticas en filosofía. Pues bien, este procedimiento será tenido en cuenta al ser enumeradas las distintas reglas de interpretación de Aristóteles. Estas reglas se encuentran desperdigadas, como estamos viendo, en distintas obras de Brentano. Sin embargo, nos atendremos aquí al elenco recogido en el pequeño ensayo dedicado a esta cuestión ${ }^{56}$ :

[a] La primera regla que Brentano enuncia aplica inmediatamente el principio de probabilidad antecedente a Aristóteles, de quien no se puede esperar que incurra en contradicción alguna, tal como ya vimos que aseveraba en su tesis de Habilitation. En el discurso que estudiamos se expresa de modo semejante: «[...] el método para la investigación de la doctrina de Aristóteles exige especialmente que, cuando nos encontremos ante afirmaciones oscuras o llamativas, se tenga en cuenta la antecedente improbabilidad de que éstas contengan una idea del todo impensable y un contenido del todo indigno de un pensador tan grande $»^{57}$.

[b] No se puede sospechar que dos afirmaciones de Aristóteles se contradigan entre sí «si no proceden de diversas épocas de su pensamiento filosófico» ${ }^{58}$. Estas palabras nos permiten llamar la atención sobre la comprensión evolutiva de Aristóteles defendida por Brentano, un aspecto poco conocido de su

54 «So verstößt man gegen die Gesetze der Wahrscheinlichkeitsrechnung, nach welchen eine an sich von vornherein sehr unwahrscheinliche Hypothese für die Ursache eines vorliegenden Faktums sehr wahrscheinlich, ja so gut wie gewiß werden kann, weil jede andere sonst noch ungleich unwahrscheinlicher erscheint. Es hätte zwei Hypothesen, welche einzig ein Faktum erklären können, die eine von vornherein die Wahrscheinlichkeit von 1/100, die andere aber von 1/1000000, so gewänne auf Grund der zu erklärenden Tatsache die eine doch eine Wahrscheinlichkeit von 10000 gegen 1, würde also schließlich als eine ganz überwiegend wahrscheinliche bezeichnet werden müssen» (BRENTANo, «Zur Methode der historischen Forschung auf philosophischem Gebiet», p. 91).

55 Cf. Hedwig, en: Brentano, Geschichte der Philosophie der Neuzeit, p. 327, nota 5.

56 En lo que sigue, expondremos las reglas enunciadas en Brentano, «Zur Methode aristotelischen Studien», §8, a-p, pp. 15-20, traducción española, pp. 683-688. Usaremos la enumeración alfabética empleada por Brentano mismo.

57 «Jede vernünftige historische Methode selbst verlangt vielmehr, daß in solchem Falle und immer die vorgängige Wahrscheinlichkeit berücksichtigt werde. Wenn aber dies, so verlangt speziell auch die Methode der Forschung nach der Lehre eines Aristoteles, daß man bei dunkeln oder auffallenden Äußerungen der vorgängigen Unwahrscheinlichkeit Rechnung trage, daß ein ganz undenkbarer Gedanke und ein eines so großen Denkers völlig unwürdiger Inhalt dem Satze innewohnen werde» (ibíd., pp. 12-13, traducción española, pp. 680-681).

58 «Es ist als vorgängig sehr unwahrscheinlich zu betrachten, daß verschiedene Aussprüche des Aristoteles in einem unmittelbaren und handgreiflichen Widerspruche stehen, wenn sie nicht aus verschiedenen Epochen seines philosophischen Denkens stammen» (ibíd., p. 15, traducción española, p. 683). 
interpretación. Como vemos, se refiere a ello en este ensayo que no puede datar de mucho después de 1883; pero le prestará una atención más detenida en una de sus últimas obras, que vio la luz en 1911. Leemos, pues, unas palabras escritas algo más de una década antes del célebre trabajo de Jaeger ${ }^{59}$ que determinó los estudios aristotélicos del siglo XX en este sentido:

La cronología, sobre todo si está fundada en huellas de una evolución doctrinal, puede tener transcendental importancia para la comprensión y ordenamiento sistemático de los varios sectores doctrinales. En Platón es, desde luego, innegable un gradual desarrollo de pensamiento. ¿Cómo había de escapar Aristóteles a esa ley de transformación? Sin duda es éste el caso si se retrocede hasta la época en que escribió sus diálogos. Aun los pocos fragmentos conservados dan testimonio de ello ${ }^{60}$.

Sin embargo, Brentano pone en cuestión el hipercriticismo evolucionista que afectaría a las obras sistemáticas (esotéricas) tomadas por sí mismas. Según la opinión de algunos, buena parte de aquellas afirmaciones que parecen entrar en contradicción con tesis defendidas tan sólo unas líneas antes serían en realidad apuntes de Aristóteles mismo inseridos con posteridad, debido a sus sucesivos cambios de parecer a lo largo del tiempo.

[c] Brentano también niega que se deban admitir contradicciones que se puedan reconocer con tal de aplicar un sencillo procedimiento; [d] esto debe rechazarse con mayor motivo cuando Aristóteles esté hablando en ese punto de aquel asunto respecto del cual sus afirmaciones se contradirían. Ahora bien, ¿cómo saber con exactitud cuál es el tema abordado en cada pasaje?, porque muchas veces el Estagirita se refiere a diversos asuntos indirectamente relacionados con el tema principal del discurso y los resuelve sobre la marcha, aunque no formen parte del asunto principal. [e] Según Brentano, se advierte el compromiso de Aristóteles con una doctrina, pese a ser expuesta en un lugar donde no tendría por qué ser tratada, no por la prolijidad con que se refiera a ella, sino por el interés que demuestra en esa cuestión y por el deleite (Genuss) de Aristóteles al mencionarlas. ¿En qué doctrinas está pensando concretamente Brentano? En la lógica de los Segundos Analíticos y en sus ideas acerca de Dios. Seguramente, aunque no lo mencione en las páginas que estamos comentando, también pensará —como hemos visto antes- en sus enseñanzas acerca del entendimiento agente.

59 Cf. JAEGER, W. W., Aristoteles. Grundlegung einer Geschichte seiner Entwicklung, Weidmann, Berlin, 1923.

60 «Auch die Frage der Chronologie der aristotelischen Schriften und die charakteristische Eigentümlichkeit, welche diejenigen unter ihnen, die man exoterisch nennt, von den sogenannten esoterischen unterscheidet, sei hier mit kurzem Worte wenigstens berührt. Die erstere, namentlich wenn Spuren einer Fortbildung der Lehre dafür den Anhalt gäben, gewänne für das Verständnis und die Zusammenordnung der einzelnen Aussprüche gewiß eine hohe Wichtigkeit. Bei Platon ist eine allmähliche Entwicklung der Lehre ganz unverkennbar. Sollte Aristoteles nicht auch zu Änderungen veranlaßt worden sein? Sicher war dies der Fall, wenn man bis auf die Zeit, wo er seine Dialoge schrieb, zurückblickt. Selbst die wenigen uns erhaltenen Fragmente bieten dafür den Beleg» (Brentano, Aristoteles und seine Weltanschauung, p. 16, trad. española, p. 26, modificada ligeramente por mí). 
[f] Tampoco se puede dar por supuesto un ánimo acomodaticio en Aristóteles, como si buscase de algún modo complacer a sus oyentes y ajustase sus palabras a lo que éstos pensaban, callando empero sus auténticos planteamientos. Esta actitud farisaica sería del todo impensable en el Estagirita, no sólo porque le convertiría en mendaz, sino sobre todo porque a quienes le adscriben semejante proceder no les empacha acusarle también de todo lo contrario: ¡dicen precisamente que cuando Aristóteles habla de los pareceres ajenos los acomoda a su propia doctrina! Después de haber tergiversado lo que piensan otros para confirmar sus puntos de vista personales, ¿cómo podría temer formular expresamente esas mismas opiniones como suyas propias? Brentano se refiere con esto a las referencias de Aristóteles a la religión popular, cosa que ha servido de pretexto a muchos - y sigue sirviendo hoy en día - para despachar rápidamente multitud de afirmaciones presentes sobre todo en los tratados de filosofía práctica. Sin embargo, Brentano está persuadido de que en esas menciones no se acomoda a la religión popular sino todo lo contrario, la contradice en puntos importantes para defender su propia visión de las cosas. Además, ¿qué hubiera debido temer, si en la Grecia de aquel tiempo no se daba ninguna supervisión de la fe religiosa por parte de autoridad alguna? Por fin, el carácter «popular» de algunos de sus escritos — como la Ética a Nicómaco- tampoco le pudo servir de excusa para decir algo distinto de lo que pensaba, pues la divulgación es bien distinta de la devaluación doctrinal.

[g] Aristóteles no ha podido enseñar nada contrario a los hechos observables en la naturaleza. Desde luego, con mayor razón hemos de desestimar dicha posibilidad cuando esté tratando el fenómeno en cuestión, máxime si lo analiza con peculiar minuciosidad.

[h] Una regla especialmente significativa del proceder de Brentano en su hermenéutica de Aristóteles exige prestar atención a la guía que proporcionan al intérprete los pareceres de los pensadores «afines» (verwandt) al filósofo estudiado. Recordemos aquí lo que antes vimos cuando Brentano establecía una línea sucesoria entre distintos filósofos, emparentados unos con otros. Nuestro autor parece pensar que la doctrina de Aristóteles está plasmada de tal modo en la filosofía personal de ciertos intérpretes — como santo Tomás- que las posiciones de éstos sobre los puntos más oscuros o menos declarados de Aristóteles deben inclinarnos a tomar partido a su favor para «completar» las lagunas doctrinales que el Estagirita ha dejado. [i] Esta misma afinidad nos permite remontarnos a los precedentes de Aristóteles mismo, cuando advertimos que una doctrina aristotélica podría verse como una continuación de otra presente en un pensador anterior. Esto es lo que hace Brentano, por ejemplo, cuando ve el voũ $\varsigma$ de Anaxágoras como un antecesor del Dios-pensamiento de Aristóteles $^{61}$. Del mismo modo, en el discurso de 1888 apelaba a Platón para comprender el origen del alma en Aristóteles y ponía otros ejemplos tomados

61 Cf. id., Die Psychologie des Aristoteles, pp. 192-194, esp. notas 234, 234a, 246; pp. 235236; id., Aristoteles und seine Weltanschaunng, pp. 94-97. 
de los presocráticos ${ }^{62}$. Por otro lado, la línea temporal puede seguirse también hacia la posteridad, dejándonos guiar por los discípulos de Aristóteles: así es como Brentano procede, por ejemplo, respecto del entendimiento agente, sintiéndose refrendado por Teofrasto y Eudemo ${ }^{63}$.

[j] Para entender el parecer de Aristóteles no se debe tener en cuenta tan sólo sus sentencias sino sobre todo las razones con las cuales las fundamenta. Hasta tal punto esto es importante que, si se encontraren dos afirmaciones contradictorias entre sí, debe priorizarse la que tiene una fundamentación argumentativa, pues es claro que el Estagirita ha puesto mayor esfuerzo en defenderla.

[k] El intérprete no puede contentarse con referir el parecer de Aristóteles, sino que es menester extraer corolarios de sus tesis. Ahora bien, nos habremos de acoger a las reglas antedichas si queremos adscribir a Aristóteles la consecuencia que hayamos formulado. [1] Es también parte del cometido de un comentarista experto tener en cuenta no sólo el pasaje que se está examinando cada vez, sino además el conjunto de la doctrina aristotélica. Esa visión de síntesis que permite hacer analogías entre unas doctrinas y otras es lo propio de una correcta hermenéutica filosófica. De lo contrario, el estudioso se verá entorpecido en su labor, del mismo modo como le sucedía al arqueólogo Benndorf con los pedazos de escultura o a Zeller con las perícopas de Aristóteles.

[m] No se debe esperar de Aristóteles un uso unívoco de los términos, porque les otorga deliberadamente distintos valores en distintos momentos, incluso poco después de haberles dado un significado preciso. «La ambigüedad de los términos es, por tanto, uno de los recursos más importantes para poner remedio a contradicciones aparentes ${ }^{64}$.

[n] Otro expediente crítico que ha de ser tratado con precaución son los hápax, pues hay una tendencia general a sacar consecuencias algo apresuradas de ellos. Según Brentano, más que en el término como tal habría que fijarse en la singularidad semántica, pues es más importante que se dé un sentido concreto tan sólo en una ocasión, que aparezca una sola vez cierta expresión no usada en ningún otro lugar - la cual bien podría ser sinónima de otra-. Lo mismo habría que aplicarlo a los descuidos aislados: teniendo en cuenta cómo se compusieron las obras de Aristóteles, raro sería que no haya más. [o] A decir verdad, los textos aristotélicos nos han llegado de un modo algo precario y desde luego no en su totalidad. No deberían producirnos extrañeza tampoco

62 «Ich komme zu einem zweiten wichtigen Mittel, das denselben Zwecken dient und meist nicht gebührend von den Historikern berücksichtigt wird. Es ist die Vergleichung einer Lehre mit dem, was sich bei Vorgängern und Nachfolgern findet. Oft besteht da eine Verwandtschaft, sei es in den Lehren selbst, sei es in den für sie maßgebenden Gründen» (id., "Zur Methode der historischen Forschung auf philosophischem Gebiet», p. 86).

63 Cf. id., Die Psychologie des Aristoteles, pp. 224-225.

${ }^{64}$ «Die Vieldeutigkeit der Termini [ist] daher eines der wichtigsten Hilfsmittel der Lösung scheinbarer Widersprüche» (id., "Zur Methode der historischen Forschung auf philosophischem Gebiet», p. 18, traducción española, p. 686). 
sus lagunas doctrinales. Por este motivo, es menester «completar los huecos» (Lücken ausfüllen) de las doctrinas aristotélicas de modo que el esqueleto de su pensamiento resulte íntegro, que no nos quede - por seguir con la metáfora tomada de Cuvier - un animal amorfo y mutilado. He aquí por qué es tan importante hallar afinidades entre Aristóteles y otros pensadores anteriores y posteriores. Brentano encuentra algunas inclusive con su admirado Leibniz, a quien empero niega haber conocido al Estagirita como hubiera sido menester: pero ¡cuánto le hubiera gustado, teniendo tantas cosas en común con él! ${ }^{65}$

[p] Brentano acaba la enumeración de sus reglas declarando que se debe recurrir antes a aquellas que nos permitan llevar a cabo una inteligente hermenéutica filosófica, que acudir enseguida a las emendaciones textuales o a los reproches a Aristóteles sea por el estilo, sea por sus descuidos, sea por sus contradicciones. Con este propósito, se detiene por fin en Torstrik, a quien estudió en su juventud, como ejemplo de un autor que enseguida se apresura a emendar el texto, desconfiando en exceso de la tradición ${ }^{66}$. Por eso se habría apartado muchas veces de la lectio difficilior y habría considerado redundantes muchas palabras que en realidad no lo son.

\section{Conclusiones}

El recorrido que hemos llevado a cabo nos ha permitido advertir cómo comprende Brentano el estudio de la filosofía de Aristóteles. Por una parte, hemos visto que su formación condicionó considerablemente las posturas adoptadas por él. Por otra parte, pese al gran aprecio del que para él siempre gozó santo Tomás de Aquino, sus estudios en el seno del neotomismo alemán, lejos de bloquearle en unos esquemas doctrinales fijos, le facilitaron sumarse al proyecto filosófico de Trendelenburg, quien contribuyó a que concibiera el estudio de Aristóteles como un ejercicio de filosofía y no sólo de historia. Ésta es la aportación principal de Brentano a este respecto: otorgar primacía a la hermenéutica filosófica por delante de ningún otro recurso. Por supuesto, nunca desdeñó los conocimientos históricos ni la crítica textual, sin embargo estos utensilios fueron para él tan sólo auxiliares y pueden llegar a ser contraproducentes de no

65 «Sehr lehrreich ist schon die vielfache Annäherung, ja Übereinstimmung der aristotelischen Weisheitslehre mit der unseres großen Leibniz» (id., Aristoteles und seine Weltanschauung, p. v); «Wie ganz anders wäre das gewesen, wenn er [sc. Leibniz] die wahre Lehre des Aristoteles gekannt hätte! Mit welchem Entzücken würde er dann auf so manchen mit der seinigen übereinstimmenden Zug verwiesen haben!» (ibíd., p. 14, en este libro hace muchas alusiones más a Leibniz). Cf. id., «Übereinstimmende Sätze bei Aristoteles und Leibniz», publicado dentro de «Unbekannte Manuskripte Franz Brentanos veröffentlicht von Samuel Hugo Bergmann», en: Franck, J., Minkowski, H. and Sternglass, E. J. (eds.), Horizons of a Philosopher Essays in Honor of David Baumgardt, Brill, Leiden, 1963, pp. 34-49.

${ }_{66}$ Ya le hacía ese reproche en su tesis de Habilitation: cf. Brentano, Die Psychologie des Aristoteles, p. 152, nota 111 (hacia el final), trad. española, p. 209. Se refiere a ToRsTRIK, A., Aristotelis De anima libri tres, Weidmann, Berlin, 1862. 
ir acompañados de la pertinente reflexión filosófica. Por este motivo y no otro, santo Tomás siempre fue admirado como el mejor intérprete de Aristóteles de todos los tiempos a los ojos de Brentano. Este aprecio no se debió a que nuestro filósofo perseverase en las doctrinas tomistas, de las que, desde su juventud, discrepó en puntos no poco importantes; más bien debemos atribuirlo a que Tomás recurriese a Aristóteles para llegar a ser filósofo y no para ejercitarse como un mero historiador. Es éste el itinerario personal de Brentano, quien se acercó inicialmente a Aristóteles como quien se arrima a un maestro, pero no para seguirlo servilmente en todas sus enseñanzas sino para aprender el quehacer filosófico y, una vez alcanzada la madurez, cumplir esa faena por cuenta propia; eso sí, sin omitir nunca el agradecimiento justamente debido a su mentor.

Por fin, aunque sean discutibles en algunos puntos, las reglas hermenéuticas propuestas por Brentano no deberían ser desoídas hoy en día; en efecto, es evidente que en los estudios aristotélicos y de filosofía clásica en general no siempre se investiga a los autores con el dominio filosófico que sería deseable, confiando el éxito de la empresa sobre todo a los conocimientos lingüísticos y filológicos. Por otro lado, debido a los acercamientos analíticos o anti-holísticos en boga, con frecuencia se echa en falta una visión sintética del conjunto de la obra de Aristóteles. Ojalá se multipliquen los modernos intérpretes que logren aunar en sí los altos conocimientos de la lengua griega y de la crítica textual que dominaba Brentano con una análoga brillantez filosófica. Podría ser que, con una dosis de precaución un tanto mayor que la suya al especular, se lograsen unos resultados todavía más luminosos que los ofrecidos por el genial pensador alemán.

\section{Bibliografía}

Obras, ediciones y traducciones de Brentano citadas

Brentano, F., Von der mannigfachen Bedeutung des Seienden nach Aristoteles, Herder, Freiburg im Breisgau, 1862.

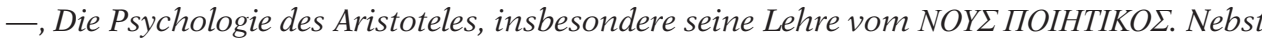
einer Beilage über das Wirken des Aristotelischen Gottes, Franz Kirchheim, Mainz, 1867. Traducción inglesa de George, R., University of California, Berkely/Los Angeles/London, 1977. Traducción española de Torrijos-Castrillejo, D., Ediciones Universidad San Dámaso, Madrid, 2015.

—, "Geschichte der kirchlichen Wissenschaften», en: MöHLER, J., A. (ed.), Kirchengeschichte, Band 2, Manz, Regensburg, 1867, pp. 526-584, traducción española de ToRrijos Castrillejo, «Franz Brentano y Tomás de Aquino», en Espíritu 65 (2016), pp. 530-538.

—, Über den Creatianismus des Aristoteles, C. Gerold's Sohn, Wien, 1882.

—, Aristoteles Lehre von Ursprung des menschlichen Geistes, Veit \& Comp., Leipzig, 1911.

—, Aristoteles Lehre vom Ursprung des menschlichen Geistes, Meiner, Hamburg, ${ }^{2} 1980$. 
-, Offener Brief an Herrn Professor Eduard Zeller aus Anlaß seiner Schrift über die Lehre des Aristoteles von der Ewigkeit des Geistes, Duncker \& Humblot, Leipzig, 1883.

—, «Thomas von Aquin», en: Neue Freie Presse 15683 (18/4/1908), pp. 1-5, traducción española de TorRiJos Castrillejo, «Franz Brentano y Tomás de Aquino», en Espíritu 65 (2016), pp. 539-555.

-, Aristoteles und seine Weltanschauung, Quelle \& Meyer, Leipzig, 1911. Traducción española de SÁnchez BARRADo, M., Labor, Barcelona, 1983.

-, Brief an Ch. B. Schlüter, 16. Februar 1863, en: NetTesheim, J., «Christoph Bernhard Schlüter und Franz Brentano. Zwei unbekannte Briefe Brentanos», en: Zeitschrift für Philosophische Forschung 16 (1962), pp. 294-296.

—, «Unbekannte Manuskripte Franz Brentanos veröffentlicht von Samuel Hugo Bergmann», en: Franck, J., Minkowski, H. and Sternglass, E. J. (eds.), Horizons of a Philosopher Essays in Honor of David Baumgardt, Brill, Leiden, 1963, pp. 34-49.

-, en: Kraus, O. (ed.), Über die Zukunft der Philosophie nebst den Vorträgen Über die Gründe der Entmutigung auf philosophischen Gebiet, Über Schellings System sowie den 25 Habilitationsthesen, Meiner, Hamburg, 1968.

—, en: Hedwig, K. (ed.), Geschichte der mittelalterlichen Philosophie, Meiner, Hamburg, 1980.

—, en: George, R. (ed.), Über Aristoteles. Nachgelassene Aufsätze, Meiner Hamburg, 1986.

—, "Zur Methode aristotelischen Studien, und zur Methode geschichtlicher Forschung auf philosophischem Gebiet überhaupt», en George, R. (ed.), Über Aristoteles. Nachgelassene Ausfsätze, Meiner Hamburg, 1986, pp. 7-20. Traducción española de ToRRIJos-Castrillejo, D. «El método de estudio de Aristóteles según Brentano», en: Anales del Seminario de Historia de la Filosofía 33 (2016), pp. 671-688.

—, en: Hedwig, K. (ed.), Geschichte der Philosophie der Neuzeit, Meiner, Hamburg, 1987.

\section{Bibliografía secundaria}

Berti, E., Aristotele nel Novecento, Laterza, Roma, 2008.

—, «Zeller e Aristotele», en: Berti, E., L'influenza di Aristotele: Età moderna e contemporanea, vol. 4.2, Nuovi studi aristotelici, Morcelliana, Brescia, 2010, pp. 121-138.

Bonitz, H., Zur Erinnerung an Friedrich Adolf Trendelenburg, Vortrag gehalten am Leibnitztage 1872 in der königlichen Akademie der Wissenschaften, Akademie der Wissenschaften, Berlin, 1872.

Freudenthal, H. W. L., «Kulturkampf», en: New Catholic Encyclopedia, vol. 8, McGrawHill, New York, 1967, pp. 267-269.

Gallardo, S., «Brentano y el Aquinate», en: Espíritu 53 (2004), pp. 279-295.

George, R. and Koenn, G., «Brentano's Relation to Aristotle», en: Jacouette, D. (ed.), The Cambridge Companion to Brentano, Cambridge UP, Cambridge, 2004, pp. 20-44.

GiLson, É., «Franz Brentano's Interpretation of Medieval Philosophy», en: McAlister, L. L. (ed.), The Philosophy of Brentano, Duckworth, London, 1976, pp. 56-67.

Hedwig, K., «Brentano’s Hermeneutics», en: Topoi 6 (1987), pp. 3-10.

—, «Eine gewisse Kongenialität'. Brentanos Rückgriff auf Thomas von Aquin in seiner Dissertation», en: TĂnĂsescu, I. (ed.), Franz Brentano's Metaphysics and Psychology, Zeta, Bucharest, 2012, pp. 95-131.

Heidegger, M., Gesamtausgabe, Band 15, Klostermann, Frankfurt am Main, 1986.

JAEGER, W., Aristoteles. Grundlegung einer Geschichte seiner Entwicklung, Weidmann, Berlin, 1923. 
Kraus, O., Franz Brentano. Zur Kenntnis seines Lebens und seiner Lehre. Mit Beiträgen von Carl Stumpf und Edmund Husserl, Beck, München, 1919.

Mangiagalli, M., Franz Brentano, interprete di Aristotele, Aracne, Roma, 2009.

Morgott, F. von P., «Aristoteles und die katholische Wissenschaft», en: Der Katholik 41 (1862), pp. 257-275.

Münch, D., "Die Einheit von Geist und Leib. Brentanos Habilitationsschrift über die Psychologie des Aristoteles als Antwort auf Zeller», en: Brentano Studien 6 (1995/6), pp. 125-144.

-, "Franz Brentano und die katholische Aristoteles-Rezeption», en: Chrudzimski, A., Huemer, W. (eds.), Phenomenology and Analysis. Essays in Central European Philosophy, Ontos, Frankfurt, 2004, pp. 159-198.

Ross, W. D., "Book Review of Franz Brentano. Aristoteles Lehre vom Ursprung des Menschlichen Geistes», en: Mind 23 (1914), pp. 289-291.

Russo, A., "San Tommaso ed Aristotele nella formazione di Franz Brentano», en: Angelicum 1 (2013), pp. 247-278.

Thouard, D. (ed.), Aristote au XIXe siècle, Septentrion, Villeneuve d'Ascq, 2004.

Tomasi, P., Una nuova lettura dell'Aristotele di Franz. Brentano alla luce di alcuni inediti, Uni Service, Trento, 2009.

Torstrik, A., Aristotelis De anima libri tres, Weidmann, Berlin, 1862.

Trendelenburg, A., Historische Beiträge zur Philosophie, 1. Band, Bethge, Berlin, 1846.

Volpi, F., «War Franz Brentano ein Aristoteliker?», en: Feilchenfeldt, K., ZaGari, L. (eds.), Die Brentano. Eine europäische Familie, Niemeyer, Tübingen, 1992, pp. 129-145.

Zeller, E., Aristoteles und die alten Peripatetiker, vol. 2.2, Die Philosophie der Griechen in ihrer geschichtlichen Entwicklung, Fues, Leipzig, ${ }^{3} 1879$.

—, "Über die Lehre des Aristoteles von der Ewigkeit des Geistes», en: Sitzungsberichte der königlich preußischen Akademie der Wissenschaften zu Berlin 1 (1882), pp. 10331055.

-, Grundriss der Geschichte der griechischen Philosophie, Fues, Leipzig, 1883.

—, en: Leuze, O. (ed.), Eduard Zellers Kleine Schriften, 1. Band, Reimer, Berlin, 1910.

Universidad Eclesiástica San Dámaso (Madrid)

David ToRriJos-CASTRILlEJO

torrijoscatrillejo@gmail.com

[Artículo aprobado para publicación en diciembre de 2016] 